\title{
Simulation of a Research Data Centre Room in an Academic Campus
}

\author{
Khaled Alsharif, Kyosung Choo ${ }^{1}$ \\ ${ }^{1}$ Mechanical and Industrial Engineering Department, \\ Youngstown State University, Youngstown, OH 44555, United States \\ kchoo@ysu.edu
}

\section{Extended Abstract}

Data centers are forty times more energy-intensive than conventional office buildings [1]. The amount of electricity consumed by data centers is equivalent to the amount consumed by 5.8 million average U.S. households and is similar to the quantity used by the entire U.S. transportation manufacturing industry [2]. Data center energy efficiency is now considered the chief concern of these centers, followed by availability and security as the second and third concerns, respectively [3-5].

In the present study, simulation studies were performed to evaluate energy performance and savings for a data center room at the Youngstown State University campus. The IT, cooling, and electrical loads were measured to compare the simulation model and suggest Energy Conservation Measure (ECM). The inlet and outlet temperature of the servers for the baseline model are well matched with the measure data within $5 \%$ error.

The ECM model is developed by separating the cold inlet flow and hot outlet flow. The ECM and its respective energy saving were identified and suggested as measures to reduce energy consumption by optimizing the thermo-fluid flow in the data center room. Partitions were attached at the center of the data center room in order to separate the cold inlet and hot outlet. The maximum rack inlet and outlet temperatures of the based model are $26.6{ }^{\circ} \mathrm{C}$ and $31.1{ }^{\circ} \mathrm{C}$, respectively. The maximum rack inlet and outlet temperatures of the ECM model are $14.8{ }^{\circ} \mathrm{C}$ and $26.9{ }^{\circ} \mathrm{C}$, respectively. Which means the ECM model has $11.8^{\circ} \mathrm{C}$ and $4.2^{\circ} \mathrm{C}$ lower temperatures at the rack inlet and outlet compare to the baseline model. Based on the ECM model, we can increase $11.8^{\circ} \mathrm{C}$ of the room set point temperature, which reduces energy consumptions of the data center room by moving the ASHRAE thermal guideline box [6].

\section{References}

[1] L. Liu, Q. Zhang, J. Zhai, C. Yue, X. Ma, State-of-the-art on thermal energy storage technologies in data center, Energy and Buildings, 226 (2020) 2-18.

[2] U.S. Environmental Protection Agency Energy Star Program, Report to Congress on Server and Data Center Energy Efficiency Public Law 109-431, Aug. 2, 2007.

[3] H.S. Sun and S.E. Lee, Case study of data centers' energy performance, Energy and Building 38 (2006) 522 - 533.

[4] J. Cho and B.S. Kim, Evaluation of air management system's thermal performance for superior cooling efficiency in high-density data centers, Energy and Building 43 (2011) 2145 - 2155.

[5] K. Choo, R. M. Galante, M. M. Ohadi, "Energy consumption analysis of a medium-size primary data center inan academic campus," Energy and Buildings, 76 (2014) 414-421.

[6] ASHRAE TC9.9, Thermal Guidelines for Data ProcessingEnvironments_Expanded Data Center Classes and Usage Guidance (2011). 